\title{
A Correction for Land Contamination of Atmospheric Variables near Land-Sea Boundaries*
}

\author{
A. Birol Kara, Alan J. Wallcraft, and Harley E. Hurlburt \\ Oceanography Division, Naval Research Laboratory, Stennis Space Center, Mississippi
}

(Manuscript received 18 February 2005, in final form 18 May 2006)

\begin{abstract}
Ocean models need over-ocean atmospheric forcing. However, such forcing is not necessarily provided near the land-sea boundary because 1) the atmospheric model grid used for forcing is frequently much coarser than the ocean model grid, and 2) some of the atmospheric model grid over the ocean includes land values near coastal regions. This paper presents a creeping sea-fill methodology to reduce the improper representation of scalar atmospheric forcing variables near coastal regions, a problem that compromises the usefulness of the fields for ocean model simulations and other offshore applications. For demonstration, atmospheric forcing variables from archived coarse-resolution gridded products-the $1.125^{\circ} \times 1.125^{\circ} 15$-yr European Centre for Medium-Range Weather Forecasts (ECMWF) Re-Analysis (ERA-15) and $1.0^{\circ} \times 1.0^{\circ}$ Navy Operational Global Atmospheric Prediction System (NOGAPS) - are used here. A fine-resolution $\left[{ }^{1} / 25^{\circ} \times 1 / 25^{\circ} \cos (\right.$ lat $\left.)\right]$, (longitude $\times$ latitude) $(\sim 3.2 \mathrm{~km})$ eddy-resolving Black Sea Hybrid Coordinate Ocean Model (HYCOM) is then forced with/without sea-filled atmospheric variables from these gridded products to simulate monthly mean climatological sea surface temperature (SST). Using only over-ocean values from atmospheric forcing fields in the ocean model simulations significantly reduces the climatological mean SST bias (by $\sim 1^{\circ}-3^{\circ} \mathrm{C}$ ) and rms SST difference over the seasonal cycle (by $\sim 2^{\circ}-3^{\circ} \mathrm{C}$ ) in coastal regions. Performance of the creeping sea-fill methodology is also directly evaluated using measurements of wind speed at $10 \mathrm{~m}$ above the surface from the SeaWinds scatterometer on the NASA Quick Scatterometer (QuikSCAT) satellite. Comparisons of original monthly mean wind speeds from operational ECMWF and NOGAPS products with those from QuikSCAT give basin-averaged rms differences of 1.6 and $1.4 \mathrm{~m} \mathrm{~s}^{-1}$, respectively, during 2000-03. Similar comparisons performed with sea-filled monthly mean wind speeds result in a much lower rms difference $\left(0.7 \mathrm{~m} \mathrm{~s}^{-1}\right.$ for both products) during the same time period, clearly confirming the accuracy of the methodology even on interannual time scales. Most of the unrealistically low wind speeds from ECMWF and NOGAPS near coastal boundaries are appropriately corrected with the use of the creeping sea fill. Wind speed errors for ECWMF and NOGAPS (mean bias of $\geq 2.5 \mathrm{~m} \mathrm{~s}^{-1}$ with respect to QuikSCAT during 2000-03) are substantially eliminated (e.g., almost no bias) near most of the land-sea boundaries. Finally, ocean, atmosphere, and coupled atmospheric-oceanic modelers need to be aware that the creeping sea fill is a promising methodology in significantly reducing the land contamination resulting from an improper land-sea mask existing in gridded coarse-resolution atmospheric products (e.g., ECMWF).
\end{abstract}

\section{Introduction and motivation}

Heat and momentum fluxes along with air temperature and relative humidity differ greatly between ocean and land surfaces. This significant difference is due

* Naval Research Contribution Number NRL/JA/7320/04/5087.

Corresponding author address: Dr. Birol Kara, Naval Research Laboratory, Code 7320, Bldg. 1009, Stennis Space Center, MS 39529-5004.

E-mail: birol.kara@nrlssc.navy.mil mainly to land-sea heterogeneity such as the land roughness, which can be significantly larger than ocean roughness (e.g., Stull 1988; Mahrt 2000). In particular, determination of the sensible and latent heat fluxes and momentum flux over land depends mainly on the physical variables of the soil, such as soil thermal and hydraulic conductivity, vegetation, and soil heat capacity (e.g., Beljaars and Holtslag 1991). While ocean heat capacity is much greater, such factors are absent or their oceanic analogs show minimal variation in the determination of these fluxes over the sea surface (Donelan et al. 1997; Bourassa et al. 1999). Different albedo and heat conduction at land and ocean surfaces 
are also major factors, resulting in large differences in net absorbed solar radiation (Offerle et al. 2003).

Ocean general circulation model (OGCM) simulations generally depend on atmospheric forcing, namely, momentum flux (i.e., wind stress) and scalar fields (e.g., net shortwave and longwave radiation fluxes at the sea surface, air temperature and, air mixing ratio at $10 \mathrm{~m}$ above the sea surface) from gridded weather prediction models. Examples of such atmospheric forcing sources include the 15-yr European Centre for Medium-Range Weather Forecasts (ECMWF) Reanalysis (ERA-15) (Gibson et al. 1999) and the Fleet Numerical Meteorology and Oceanography Center (FNMOC) Navy Operational Global Atmospheric Prediction System (NOGAPS) (Rosmond et al. 2002).

A serious problem arises when using the preceding coarse-resolution products $\left(1.125^{\circ} \times 1.125^{\circ}\right.$ for ERA15 , and $1.0^{\circ} \times 1.0^{\circ}$ for NOGAPS) in forcing fineresolution, eddy-resolving OGCMs, such as the $1 / 25^{\circ} \times$ $1 / 17^{\circ}$ (latitude $\times$ longitude) model of Beckers et al. (2002) and the $1 / 25^{\circ} \cos ($ lat $) \times 1 / 25^{\circ}$ (latitude $\times$ longitude) model of Kara et al. (2005a). This problem exists because atmospheric forcing values (e.g., near-surface air temperature and wind speed) over water during interpolation to the finer ocean grid are contaminated by values over land near coastal regions, mainly because of the much coarser atmospheric computational grid. An example of this problem is already mentioned in Kara et al. (2005b).

Given the preceding disadvantages in using gridded atmospheric data products to force OGCMs near coastal regions, special action is required to ensure that land values in scalar atmospheric forcing variables are not used in forcing ocean model simulations. Mitigating solutions to such problems are especially needed for coastal and nested OGCM studies. In this paper, we investigate the possibility that these errors can be reduced using a creeping sea fill, an interpolation technique that reduces land contamination over the sea grid points near coastal regions.

\section{Description and application of the creeping sea fill}

The model near-surface grid in coarse-resolution atmospheric products (e.g., ERA-15 and NOGAPS) is logically divided into sea and land points. This division is accomplished by using a land-sea mask. A grid point in both products is defined as a land point if more than $50 \%$ of the actual surface of the grid box is land. The original land-sea masks in the ERA-15 and NOGAPS data are represented as values 0 (for sea) and 1 (for land).
The Black Sea is particularly chosen to investigate possible applications of creeping sea fill as it has a wide continental shelf in some regions (Fig. 1). The Black Sea is therefore an ideal candidate to illustrate the land contamination issues from coarse-resolution atmospheric forcing products, such as ERA-15 and NOGAPS.

The $1.125^{\circ} \times 1.125^{\circ}$ reduced Gaussian grid for ERA15 and $1.0^{\circ} \times 1.0^{\circ}$ for NOGAPS are interpolated to an $\sim 3.2 \mathrm{~km}$ resolution Black Sea OGCM domain (Fig. 2a). The OGCM is briefly described in section 3 . The interpolated representation of the original land-sea mask on the OGCM grid clearly reveals that some of the ocean points are contaminated by land values. For example, a contour value of 0.8 in the land-sea masks implies that the interpolated atmospheric forcing variables, such as near-surface air temperature (e.g., 2 or $10 \mathrm{~m}$ above the sea surface), are $\sim 80 \%$ contaminated by land values on the OGCM grid. This contamination is especially evident over the northwestern and southeastern shelves in the interpolated ERA-15 land-sea mask (Fig. 2a). All ocean grid points south of $42.0^{\circ} \mathrm{N}$ are contaminated by land in the ERA-15 land-sea mask as well. ERA-15 has only one sea grid point east of $39^{\circ} \mathrm{E}$, although there should be two to three grid points based on the $50 \%$ ocean rule. NOGAPS provides a better representation of the land-sea distribution than ERA-15. However, it is still limited by its $1.0^{\circ} \times 1.0^{\circ}$ resolution.

The creeping sea fill is one method for eliminating the land contamination described above. Interpolation methods designed for irregularly spaced data (Burrough and McDonnell 1998) are examples of alternatives. The creeping sea fill simply means that atmospheric forcing variables are postprocessed so that only over-sea values can be used. It replaces the value associated with each land-masked point by one using only nearby sea values.

The creeping-fill scheme makes multiple passes through the array, and on each pass, for each unfilled point, calculates the weighted sum of the eight nearest points (i.e., over the compact nine-point stencil) with a weight of zero at unfilled points, a weight of two at any of the four north, south, east, or west points that have values, and similarly a weight of one at the four diagonal points. The target point is filled if the weights sum to at least three. This is a "creep fill" because each pass through the array only provides values near to the filled/unfilled boundary from the previous pass. The scheme uses only a very few of the nearest sea points when close to the original land-sea boundary and does not use values from both sides of an isthmus (e.g., does not use both Atlantic and Pacific values in filling points near Central America). The atmospheric arrays are 


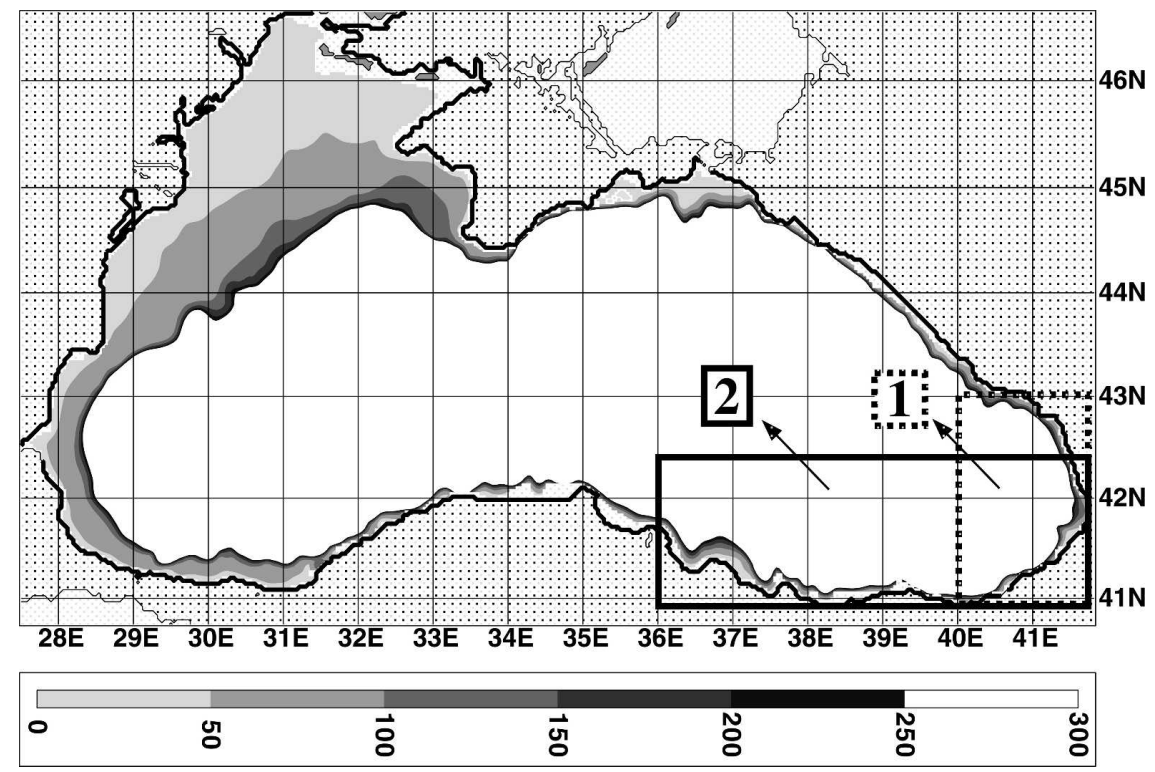

FIG. 1. Bottom topography of the Black Sea, designed to show shallow water depths. The region in white shows depths $>250 \mathrm{~m}$. Two boxes marked in the southeastern part of the Black Sea are used in sections 3 and 4 to demonstrate possible impacts of the creeping sea fill, applied to scalar atmospheric forcing variables, near coastal boundaries.

creep filled on the original atmospheric grid and are best interpolated to finer oceanic grids using bilinear interpolation since this minimizes the influence of filled values.

As an example, Fig. 2b illustrates an application of the creeping sea-fill methodology to the reduction of the land-contaminated climatological mean values from near-surface air temperature fields. Results are shown from ERA-15 spanning 1979-93 and NOGAPS spanning 1998-2002 before and after the application. Air temperature and wind speed just above the sea surface are in particular need of correction, when used in atmospheric forcing for OGCM simulations, because they have great influence on the sea surface temperature (SST) via the latent heat flux, especially near coastlines where advection by the mean wind and the vertical flux divergence can become significant (Samelson 1992). Note that near-surface air temperature from ERA-15 is at $2 \mathrm{~m}$, while that from NOGAPS is at $10 \mathrm{~m}$ above the sea surface. Since the traditional log-profile assumptions are not valid at very low wind speeds (e.g., near the center of subtropical highs), the adjustment from 2 to $10 \mathrm{~m}$ is not straightforward. Currently available algorithms usually fail for these cases, as we have tested (not shown). Thus, no attempt was made to adjust air temperature from 2 to $10 \mathrm{~m}$. This neglect is acceptable given the fact that such a height adjustment is very small on climatological time scales.
A creeping sea-fill interpolation is applied to nearsurface air temperatures from ERA-15 and NOGAPS. This process only uses air temperatures that do not have any land contamination; that is, only values inside the "white" region in Fig. 2a are used for the extrapolation. The resulting fields are thus extrapolated into regions near the coast. The impact of this process on the results is quite remarkable since most of the unrealistic air temperature values near the coastal regions are removed from the original field. For example, Schrum et al. (2001) confirmed that the nearsurface air temperature from ERA-15 is unrealistically low in comparison to the climatic data from observation-based climatologies in the southeastern Black Sea. Thus, results shown in Fig. 2b clearly demonstrate the unrealistically low temperatures found in the archived coarse-resolution gridded products that were largely eliminated after applying the creeping sea fill, resulting in accurate (i.e., warmer) air temperatures over coastal waters. After the creeping sea fill is applied, near-surface air temperature does not change in the interior where the methodology does not have any effect.

Replacing the land values of vector fields, such as wind stress, would also lead to improved over-ocean fields, but is significantly more difficult to do well. This difficulty is due to the fact that correcting wind speed alone does not provide any guarantee of accurate di- 
(a) Land-sea masks interpolated onto the HYCOM grid

ERA-15 land-sea mask

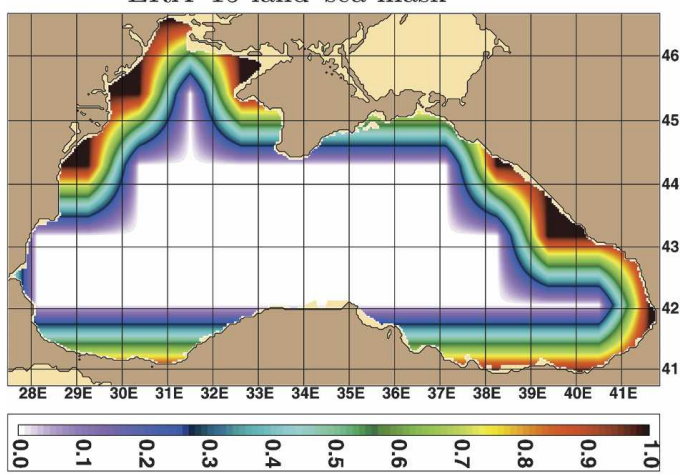

(b) Air temperature $\left({ }^{\circ} \mathrm{C}\right)$ in February before and after the creeping sea-fill

ERA-15 air temperature

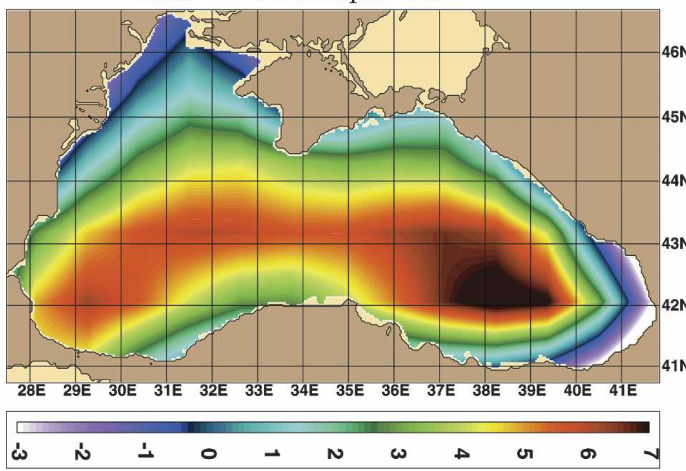

After applying the creeping sea-fill

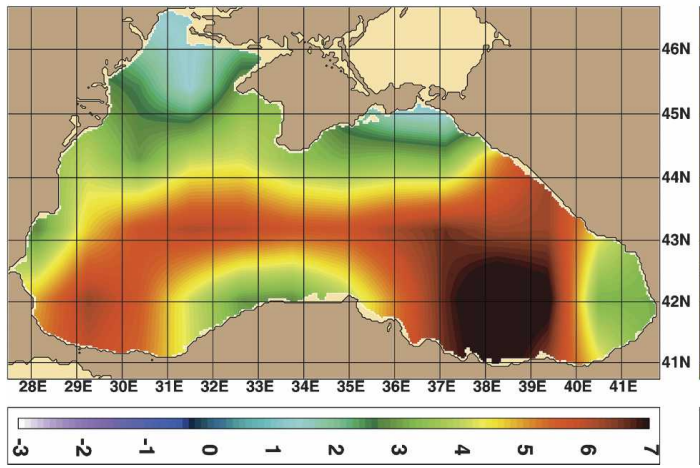

FIG. 2. (a) The land-sea masks interpolated to the $\sim 3.2-\mathrm{km}$-resolution Black Sea model grid from two archived gridded products: ERA-15 and NOGAPS. (b) Near-surface air temperature before and after applying the creeping sea fill, as described in the text in detail.

rection. However, results presented in section 4 show promise that wind speed can be easily corrected using the creeping sea fill. The methodology can be applied to zonal and meridional wind speed components from ERA-15 and NOGAPS, separately. Wind stress can then be calculated using a bulk formulation, potentially reducing the errors in wind stress and wind stress curl near land-sea boundaries-a possibility not tested here.
NOGAPS land-sea mask

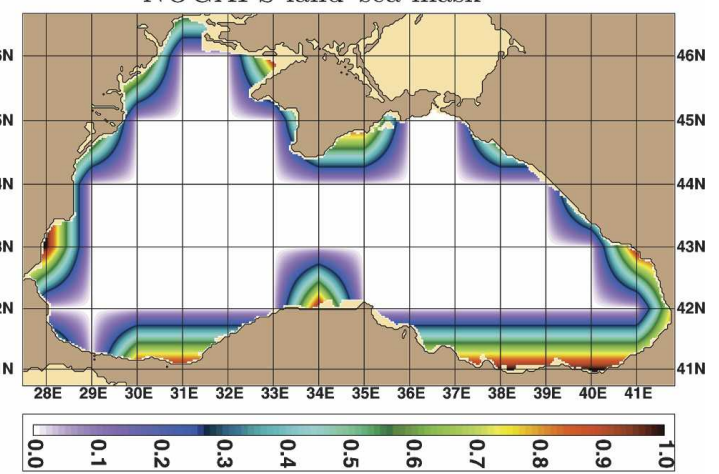

NOGAPS air temperature

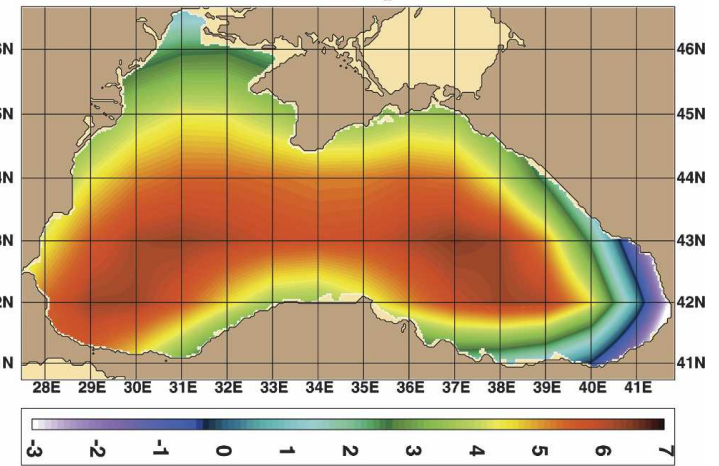

After applying the creeping sea-fill

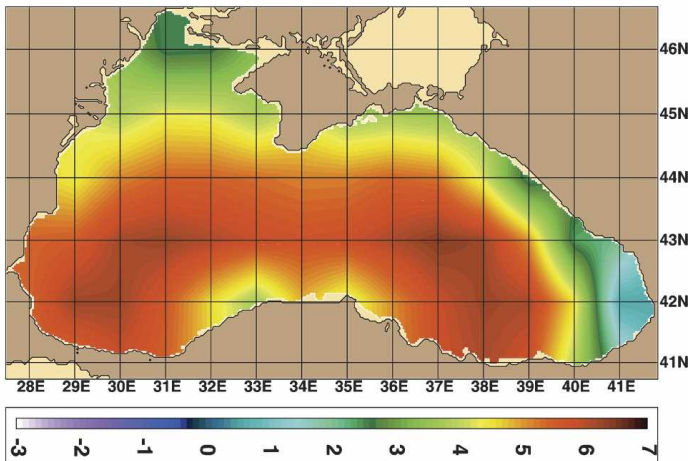

\section{Application to an ocean model}

An eddy-resolving Hybrid Coordinate Ocean Model (HYCOM) has been implemented for the Black Sea simulations and then used in examining the impact of the sea-filled atmospheric forcing fields in improving model results near coastal regions.

HYCOM is a community ocean model (see information online at http://oceanmodeling.rsmas.miami.edu/ 
hycom/). It behaves like a conventional $\sigma$ (terrain following) model in very shallow oceanic regions, like a $z$-level coordinate model in the mixed layer, or other unstratified regions, and like an isopycnic coordinate model in stratified regions. The transition between coordinate types is made dynamically in space and time via the layered continuity equation (Bleck 2002). The mixed layer/vertical mixing options in HYCOM are evaluated in Halliwell (2004). The model simulations presented in this paper use a nonslab K-profile parameterization (KPP) mixed layer submodel (Large et al. 1997). The Black Sea model has a resolution of $1 / 25^{\circ} \times$ $1 / 25^{\circ} \cos ($ lat) (longitude $\times$ latitude; $\sim 3.2 \mathrm{~km}$ ). There are 15 hybrid layers (10 predominantly isopycnal and 5 always $z$ or $\sigma$ levels), and the model land-sea boundary is set at the 10-m isobath. Further details of the model setup are discussed in Kara et al. (2005a,b).

The model is first forced with the original, that is, uncorrected, atmospheric variables as directly obtained by interpolation from the ERA-15 and NOGAPS grids, separately. Twins of these simulations are then performed using the sea-filled atmospheric forcing variables (section 2). The creeping sea fill is applied to all scalar atmospheric forcing variables: air temperature and air mixing ratio at $10 \mathrm{~m}$ above the sea surface, net shortwave radiation and net longwave radiation at the sea surface, and precipitation. The climatological mean forcing used for the simulations spans the time period from 1979 to 1993 for ERA-15, and 1998 to 2002 for NOGAPS.

All HYCOM simulations presented here have no assimilation of any ocean data except initialization from climatology and weak relaxation to sea surface salinity climatology. There is no relaxation to a SST climatology and no subsurface relaxation to climatological temperature or salinity.

For evaluation of the HYCOM simulations forced with/without sea-filled atmospheric forcing, monthly mean model SSTs are formed from daily fields using the last four model years (years 5 through 8 ). They are then compared with monthly mean Pathfinder SST climatology (Casey and Cornillon 1999). The Pathfinder climatology covers 1985-97 and has a resolution of $\sim 9.3 \mathrm{~km}$; its accuracy is $\sim 0.5^{\circ} \mathrm{C}$. The Pathfinder climatology is preferred for the model-data comparisons because it has a very fine resolution, which is appropriate for the fine-resolution Black Sea model used here.

HYCOM is evaluated using time series of monthly mean SST from Pathfinder $(X)$ and HYCOM $(Y)$. The evaluation statistics are mean error (ME) and rootmean-square $(\mathrm{rms})$ difference. Let $X_{i}(i=1,2, \ldots, n)$ be the set of $n$ Pathfinder (reference) values, and let $Y_{i}$ $(i=1,2, \ldots, n)$ be the set of corresponding HYCOM values. Also, let $\bar{X}(\bar{Y})$ be the mean of the reference (HYCOM) values, respectively,

$$
\begin{aligned}
\mathrm{ME} & =\bar{Y}-\bar{X} \quad \text { and } \\
\mathrm{rms} & =\left[\frac{1}{n} \sum_{i=1}^{n}\left(Y_{i}-X_{i}\right)^{2}\right]^{1 / 2},
\end{aligned}
$$

where $n$ is 12 at each model grid point.

Spatial ME and rms maps of model SST with respect to Pathfinder are formed when HYCOM uses original or sea-filled atmospheric forcing from ERA-15 and NOGAPS, separately (Fig. 3). For the simulation using ERA-15 forcing (Fig. 3a), HYCOM already performs well in the interior of the Black Sea where there is no land contamination in the atmospheric forcing variables, almost no annual mean bias, and a rms SST difference of $\sim 1.3^{\circ} \mathrm{C}$ over the seasonal cycle.

The basin-averaged model rms SST difference with respect to the Pathfinder SST climatology is $1.4^{\circ} \mathrm{C}$ $\left(1.2^{\circ} \mathrm{C}\right.$ ) when using the original (sea filled) atmospheric forcing variables from ERA-15. The corresponding basin-averaged rms SST differences are $1.4^{\circ} \mathrm{C}\left(1.3^{\circ} \mathrm{C}\right)$ when NOGAPS forcing is used. Basin-averaged annual mean HYCOM SST error with respect to the Pathfinder SST climatology is $-0.54^{\circ} \mathrm{C}\left(-0.11^{\circ} \mathrm{C}\right)$ when using the original (sea filled) atmospheric forcing variables from ERA-15. Again, the corresponding basinaveraged annual mean SST error is $0.19^{\circ} \mathrm{C}\left(0.38^{\circ} \mathrm{C}\right)$ with NOGAPS forcing.

Unlike the interior of the Black Sea, there are very large annual mean SST biases close to the coastal boundaries when the atmospheric forcing variables based directly on the original ERA-15 land-sea mask are used. The amplitude of the annual mean SST bias between the HYCOM and Pathfinder SST is generally $>2^{\circ} \mathrm{C}$, and can even be as large as $3^{\circ} \mathrm{C}$ on the northwestern and southeastern shelves. The model has also large rms SST differences $\left(>2^{\circ} \mathrm{C}\right)$ with respect to the Pathfinder SST climatology in these regions. In contrast, the model performance improves significantly when using the sea-filled atmospheric forcing variables. The model SST bias is typically reduced by $1^{\circ}$ to $3^{\circ} \mathrm{C}$. The corresponding decrease in rms SST difference is also evident near the land-sea boundaries.

With the relatively accurate mask used in NOGAPS (see Fig. 2a), HYCOM demonstrates the ability to simulate accurate SSTs over the broad northwestern shelf in the Black Sea (Fig. 3b). Clearly, there is a striking difference over the northwestern shelf, a region of relatively good agreement for NOGAPS (rms mostly $<1.5^{\circ} \mathrm{C}$ ), but poor agreement for ERA-15 (rms mostly $>1.5^{\circ} \mathrm{C}$ ). However, there are still relatively large ME 
(a) SST statistics: HYCOM (ERA-15 forcing) versus Pathfinder.

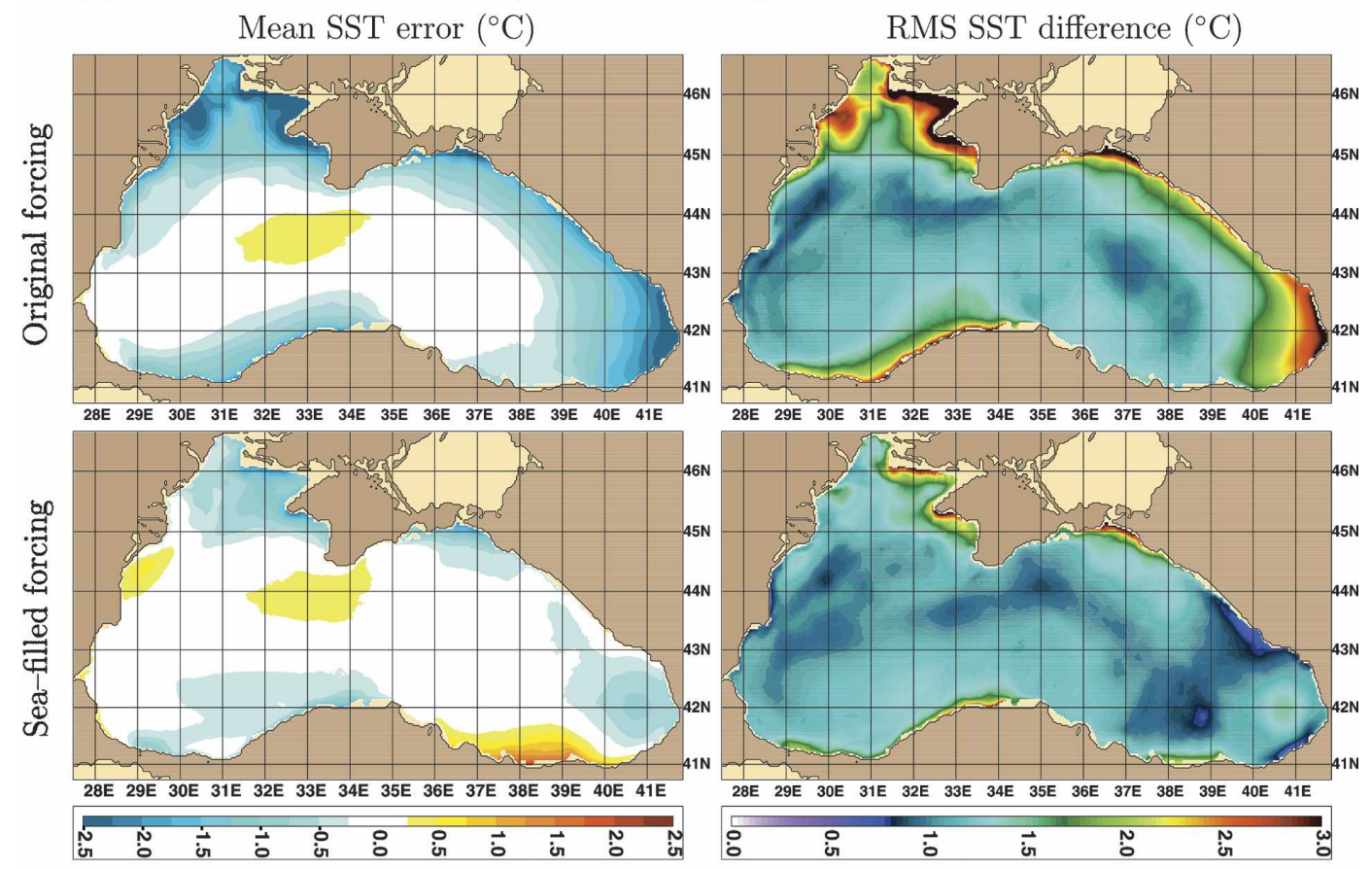

(b) SST statistics: HYCOM (NOGAPS forcing) versus Pathfinder.

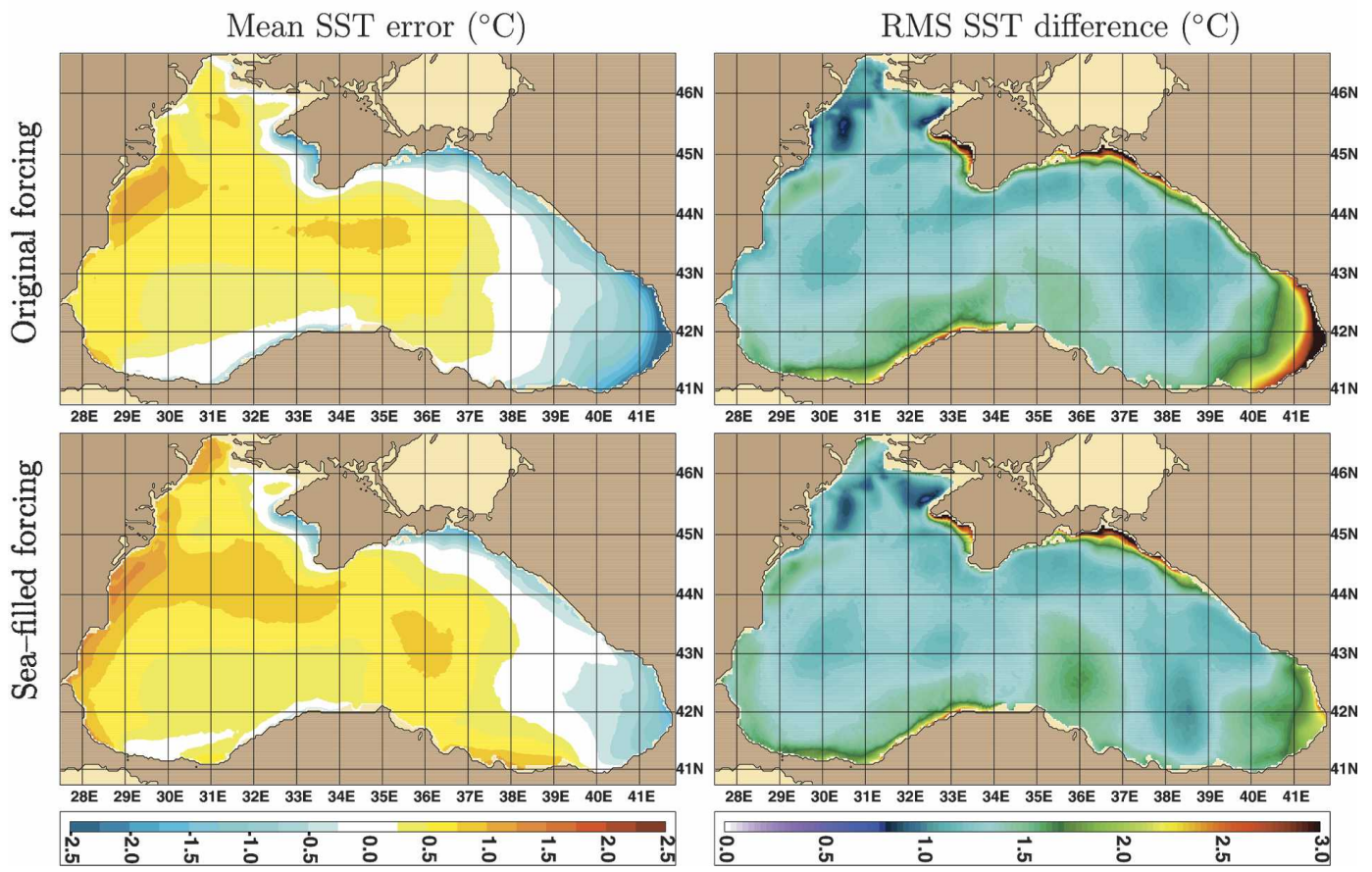

FIG. 3. Annual mean SST bias and rms SST difference of the Black Sea HYCOM with respect to the satellite-based Pathfinder SST climatology.

$\left(\sim 0.5^{\circ}-2.5^{\circ} \mathrm{C}\right)$ and $\mathrm{rms}$ SST difference values $\left(\sim 2.0^{\circ}-\right.$ $3.0^{\circ} \mathrm{C}$ and even more) when using the atmospheric forcing variables directly on the original NOGAPS landsea mask in the southeastern part of the region. Most of these errors are significantly reduced when using the sea-filled atmospheric forcing variables.

Before the creeping sea fill is applied, HYCOM simulations performed with atmospheric forcing from 


\section{- HYCOM uses uncorrected atmospheric forcing - HYCOM uses sea-filled atmospheric forcing}

(a) ERA-15 forcing
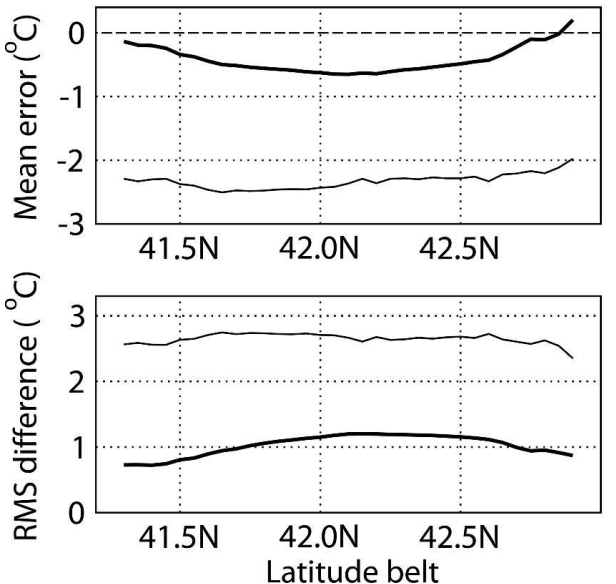

(b) NOGAPS forcing
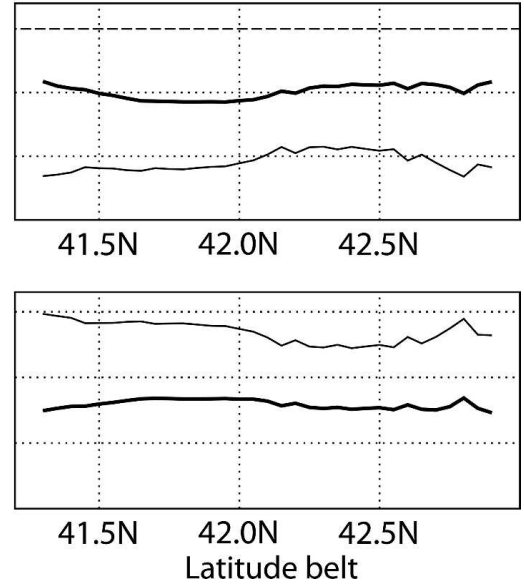

FIG. 4. Areal averages of mean SST error and rms SST difference with respect to the monthly Pathfinder SST for given latitude belts, calculated using values at all model grid points east of $40^{\circ} \mathrm{E}$ in the easternmost part of the Black Sea. The values are shown before (thin solid line) and after (thick solid line) applying the creeping sea fill to atmospheric forcing variables, when HYCOM simulations used wind and scalar forcing from (a) ERA-15 and (b) NOGAPS.

either ERA-15 or NOGAPS result in similar and large SST errors (predominantly $>2^{\circ} \mathrm{C}$ ) with respect to the Pathfinder SST east of $40^{\circ} \mathrm{E}$. These errors are significantly reduced after the creeping sea fill in the same region, but this remarkable reduction in $\mathrm{ME}$ and $\mathrm{rms}$ is much more evident in the simulation using atmospheric forcing from ERA-15. The NOGAPS land-sea mask is more accurate than the ERA-15 land-sea mask; that is, atmospheric forcing from the latter has more land contamination east of $40^{\circ} \mathrm{E}$ (Fig. 2a).

Even though the NOGAPS land-sea mask has relatively less land contamination east of $40^{\circ} \mathrm{E}$, the HYCOM simulation using atmospheric forcing from NOGAPS results in larger error in this region compared to using atmospheric forcing from ERA-15, even after the creeping sea fill is used for the scalar atmospheric forcing variables. This larger error occurs because the errors due to both contaminated and uncontaminated forcing from NOGAPS are generally larger in this area than those from ERA-15, reducing the effectiveness of the creeping sea fill.

A rigorous quantitative analysis that determines the effectiveness of the creeping sea-fill methodology is performed by examining the SST error statistics (ME and rms), obtained with uncorrected (original) versus sea-filled atmospheric forcing near coastal regions. Because model SST errors are generally large $\left(>2^{\circ} \mathrm{C}\right)$ east of $40^{\circ} \mathrm{E}$, a quantitative analysis is performed in this region. The land-sea mask for ERA-15 shows land contamination values $>80 \%$ over much of this area versus typical values of $\sim 40 \%-60 \%$ for NOGAPS (Fig. 2a).

Areal averages of mean SST error and rms SST difference are calculated using all grid points within certain distances of the model boundary in the meridional direction, starting from the southeastern boundary (longitude of $\sim 41.77^{\circ} \mathrm{E}$ ) through $40^{\circ} \mathrm{E}$, spanning the latitude belt from $40.95^{\circ}$ to $43.00^{\circ} \mathrm{N}$. See the box marked with a 1 in Fig. 1 for the region where areal averages are calculated. As a reference, we first perform the areal averaging within $55 \mathrm{~km}$ from the southeastern boundary using all model grid points within the longitude belt from $41.77^{\circ}$ to $\sim 41.1^{\circ} \mathrm{E}$. The areal averaging clearly demonstrates the success of the creeping sea fill in improving model SST simulations with respect to the Pathfinder SST within this coastal region (Fig. 4). Model SST errors are significantly decreased, clearly indicating that deficiencies in atmospheric forcing due to land contamination can have a substantial impact on simulation skill of an OGCM near land-sea boundaries.

Mean SST errors (rms SST differences) of $\sim 3^{\circ} \mathrm{C}$ $\left(\sim 3.5^{\circ} \mathrm{C}\right)$ are seen at the model grid points most affected by land contamination of the atmospheric forc- 
TABLE 1. Areal averages of mean SST error and rms SST difference with respect to the monthly Pathfinder SST. Areal averages are given within various distances from the southeastern region of the model boundary $\left(41.77^{\circ} \mathrm{E}\right.$ longitude $)$ to $40^{\circ} \mathrm{E}$ spanning latitude belts from $40.95^{\circ} \mathrm{N}$ to $43.00^{\circ} \mathrm{N}$ (see the box marked with 1 in Fig. 1) The statistics are calculated before and after the creeping sea fill is applied to the scalar atmospheric forcing variables, when HYCOM simulations used monthly mean climatological wind and scalar thermal forcing from (a) ERA-15 and (b) NOGAPS, separately.

\begin{tabular}{|c|c|c|c|c|c|c|c|c|c|c|}
\hline \multirow[b]{2}{*}{ Model SST error } & \multirow[b]{2}{*}{ Creeping sea fill } & \multicolumn{9}{|c|}{ Meridional distance $(\mathrm{km})$ from the southern model boundary } \\
\hline & & 10 & 25 & 40 & 55 & 70 & 85 & 100 & 115 & 130 \\
\hline \multicolumn{11}{|c|}{ (ERA-15) } \\
\hline \multirow{2}{*}{$\mathrm{ME} \quad\left({ }^{\circ} \mathrm{C}\right)$} & No & -3.0 & -2.8 & -2.5 & -2.4 & -2.2 & -2.1 & -2.0 & -1.9 & -1.8 \\
\hline & Yes & -0.4 & -0.4 & -0.4 & -0.5 & -0.5 & -0.5 & -0.5 & -0.5 & -0.6 \\
\hline \multirow{2}{*}{$\operatorname{Rms}\left({ }^{\circ} \mathrm{C}\right)$} & No & 3.3 & 3.0 & 2.8 & 2.7 & 2.6 & 2.5 & 2.3 & 2.3 & 2.2 \\
\hline & Yes & 1.1 & 1.0 & 1.0 & 1.1 & 1.1 & 1.1 & 1.1 & 1.1 & 1.1 \\
\hline \multicolumn{11}{|c|}{ (NOGAPS) } \\
\hline \multirow[t]{2}{*}{$\mathrm{ME}$} & No & -3.0 & -2.7 & -2.3 & -2.1 & -1.9 & -1.7 & -1.6 & -1.5 & -1.4 \\
\hline & Yes & -1.3 & -1.3 & -1.1 & -1.0 & -0.9 & -0.8 & -0.7 & -0.6 & -0.6 \\
\hline \multirow[t]{2}{*}{$\operatorname{Rms}\left({ }^{\circ} \mathrm{C}\right)$} & No & 3.5 & 3.3 & 2.9 & 2.7 & 2.5 & 2.4 & 2.3 & 2.2 & 2.1 \\
\hline & Yes & 1.9 & 1.9 & 1.8 & 1.7 & 1.6 & 1.5 & 1.5 & 1.4 & 1.4 \\
\hline
\end{tabular}

ing (e.g., 10, 25, and $40 \mathrm{~km}$ away from $41.77^{\circ} \mathrm{E}$ ) as evident from Table 1. The errors are reduced to values of $\sim-0.5^{\circ} \mathrm{C}\left(\sim 1.0^{\circ} \mathrm{C}\right)$ after the creeping fill is used to replace the scalar atmospheric forcing variables with land contamination in ERA-15. As will be explained later, the application of the creeping sea fill to the scalar atmospheric forcing variables from NOGAPS did not reduce basin-averaged model SST errors as much as it did for ERA-15, but there is still noticeable improvement in the accuracy of SST near the land-sea boundaries. This improvement is an indication of the fact that the impact of creeping sea fill in improving model SST accuracy can be quite large, even if the land contamination is small. In general, the results provided in Table 1 reveal that the simulation skill of an OGCM can be limited by the quality of the atmospheric forcing near land-sea boundaries. However, the creeping sea fill applied to scalar atmospheric variables used in forcing an OGCM can significantly improve model skill.

The basin-averaged model rms SST difference with respect to the Pathfinder SST climatology is $1.4^{\circ} \mathrm{C}$ $\left(1.2^{\circ} \mathrm{C}\right)$ when using the original (sea filled) atmospheric forcing variables from ERA-15. The corresponding basin-averaged rms SST differences are $1.4^{\circ} \mathrm{C}\left(1.3^{\circ} \mathrm{C}\right)$ when NOGAPS forcing is used. Basin-averaged annual mean HYCOM SST error with respect to the Pathfinder SST climatology is $-0.54^{\circ} \mathrm{C}\left(-0.11^{\circ} \mathrm{C}\right)$ when using the original (sea filled) atmospheric forcing variables from ERA-15. Again, the corresponding basinaveraged annual mean SST errors are $0.19^{\circ} \mathrm{C}\left(0.38^{\circ} \mathrm{C}\right)$ with NOGAPS forcing.

The improvement in SST simulation using the creeping sea fill is much less dramatic for NOGAPS than the ERA-15 forcing. This can be explained as follows. The coarse-resolution scalar atmospheric forcing variables are not the only reason for relatively large SST bias near coastal regions, which occurs to a lesser extent even when using the sea-filled atmospheric forcing as opposed to the original (uncorrected) NOGAPS or ERA-15 forcing. This is because, along with the land-sea mask problems, wind stress forcing from ERA-15 and NOGAPS near coastal regions is not very accurate when compared with remotely sensed data based on measurements from the SeaWinds scatterometer (Kara et al. 2005c). This difference is especially true on the northwestern shelf, where the annual mean HYCOM SST bias is slightly increased even when the sea-filled NOGAPS thermal forcing is used. Kara et al. (2005c) demonstrates that, when the model is forced with the NASA Quick Scatterometer (QuikSCAT) winds along with thermal forcing from either ERA-15 or NOGAPS, the agreement between HYCOM and Pathfinder SST is quite remarkable, especially in the coastal regions of the northwestern shelf.

Model simulations performed with decontaminated scalar forcing clearly demonstrate that HYCOM can simulate accurate SSTs in shallow water and near coastal regions using either ERA-15 or NOGAPS. Overall, mean SST bias and rms SST differences are reduced significantly after applying the creeping sea fill to atmospheric forcing, especially for the ERA-15forced simulations north of $45^{\circ} \mathrm{N}$ on the northwestern shelf.

\section{Comparisons against satellite winds}

The creeping sea fill presented in section 2 is clearly a useful interpolation methodology, reducing the improper representation of scalar atmospheric forcing 
variables in near-coastal regions. This improvement is indirectly demonstrated by using an OGCM in section 3. One concern is to determine the performance of the methodology directly, a subject of this section.

Accuracy and validity of the creeping sea-fill methodology are evaluated using wind speed just above the sea surface (at $10 \mathrm{~m}$ ), since OGCMs are typically forced with winds in the form of wind stress. Wind speed is particularly chosen for this evaluation for two main reasons: 1) because OGCM simulations in some coastal regions (e.g., in the Black Sea) may be much more sensitive to details in the wind forcing than to the scalar forcing (e.g., air temperature, heat fluxes, etc.) and 2) there are satellite-derived wind speed data with better spatial resolution than found in archived coarseresolution gridded products. Thus, the performance of the creeping sea fill applied to wind speed fields, obtained from the archived gridded products, can be directly evaluated near land-sea boundaries.

Wind speeds from the operational ECWMF and NOGAPS data are evaluated against those obtained from a satellite-based wind product. For this purpose, we first form monthly mean wind speeds from the original operational ECMWF and NOGAPS fields. We then apply the creeping sea-fill methodology to these fields. The original and sea-filled monthly wind speed fields are compared to the satellite wind speeds interannually to investigate the performance of the methodology. All evaluations presented here are for interannual monthly means over 2000-03, the time frame of availability for the satellite winds as of this writing.

A brief description of the construction of the monthly mean satellite winds, considered as "truth" in the comparisons, is briefly discussed here. We use daily measurements from the SeaWinds scatterometer sensor on the QuikSCAT, which provides observations of wind speed and direction over the ocean surface (see information online at http://winds.jpl.nasa.gov/ missions/quikscat/index.cfm). Further details about the remotely sensed wind data can also be found in Bourassa et al. (2003).

The SeaWinds scatterometer is an active microwave sensor that covers $\sim 90 \%$ of the ice-free ocean in one day, with an average of two observations per $25 \times 25$ $\mathrm{km}^{2}$ grid cell each day. The gaps in the daily coverage are filled by using a variational method that minimizes a function with three constraints (Pegion et al. 2000). The functional term consists of misfits to the scatterometer observations, a penalty function to smooth with respect to a background field based on spatially smoothed scatterometer observations, and a misfit to the vorticity of the background field.
Scatterometer wind retrievals are calibrated to the neutral stability wind at a height of $10 \mathrm{~m}$ above the sea surface (Chelton et al. 2001). Thus, wind speeds from QuikSCAT require stability correction to be consistent with those from ECMWF and NOGAPS. Most important is that scatterometer winds have a few shortcomings. For example, accurate determination of low wind speeds from satellites remains a major problem. In general, QuikSCAT has an accuracy of $2 \mathrm{~m} \mathrm{~s}^{-1}$ for wind speeds from 3 to $20 \mathrm{~m} \mathrm{~s}^{-1}$ and $\sim 20^{\circ}$ for wind direction (see information at http://winds.jpl.nasa.gov/). Wind observations from automated weather stations on research vessels were also used to validate winds determined from observations by the SeaWinds Scatterometer on the QuikSCAT satellite (Bourassa et al. 2003). The random uncertainty (one standard deviation) in wind speed was found to be $\sim 0.65 \mathrm{~m} \mathrm{~s}^{-1}$.

In this study, monthly mean wind speed fields from QuikSCAT are formed on a $0.5^{\circ} \times 0.5^{\circ}$ grid. For evaluations of sea-filled fields, wind speeds from ECMWF, NOGAPS, and QuikSCAT are interpolated to the fineresolution HYCOM grid (see section 2). All scatterometer winds are obtained over the water and produced with a land mask that extends $30 \mathrm{~km}$ offshore. Thus, scatterometer winds do not have any significant land contamination near the land-sea boundaries.

Scatterometers provide equivalent neutral wind speeds (Liu and Tang 1996), while 10-m wind speeds from ERA-15 analyses and NOGAPS include the effects of air-sea stability. For comparison, scatterometer winds were converted to actual winds using 6-hourly atmospheric variables from ECMWF and NOGAPS (not shown). Differences between equivalent neutral winds and actual winds are typically small $\left(<0.3 \mathrm{~m} \mathrm{~s}^{-1}\right)$ over the most of global ocean on monthly time scales.

Wind speed fields from ECMWF and QuikSCAT are compared for the same month in two different yearsJuly 2000 and July 2003. This comparison allows us to investigate the effectiveness and accuracy of the creeping sea fill in representing interannual variations (Fig. 5 ), which are typically smaller than seasonal variations. Monthly mean wind speeds from QuikSCAT are generally $\geq 2.5 \mathrm{~m} \mathrm{~s}^{-1}$ near the land-sea boundaries during both time periods (Fig. 5a). However, the original ECMWF wind fields (Fig. 5b) give unrealistically low wind speeds $\left(\leq 2.5 \mathrm{~m} \mathrm{~s}^{-1}\right)$ near coastal boundaries, especially in the southeasternmost (i.e., east of $40^{\circ} \mathrm{E}$ and south of $42^{\circ} \mathrm{N}$ ) and southwesternmost (i.e., west of $32^{\circ} \mathrm{E}$ and south of $42^{\circ} \mathrm{N}$ ) parts of the Black Sea. These are the regions where a significant amount of land contamination in the wind speed field should be expected owing to the land-sea mask (see section 2). 
(a) Wind speed magnitude $\left(\mathrm{m} \mathrm{s}^{-1}\right)$ from the SeaWinds scatterometer

QuikSCAT wind speed (July 2000)

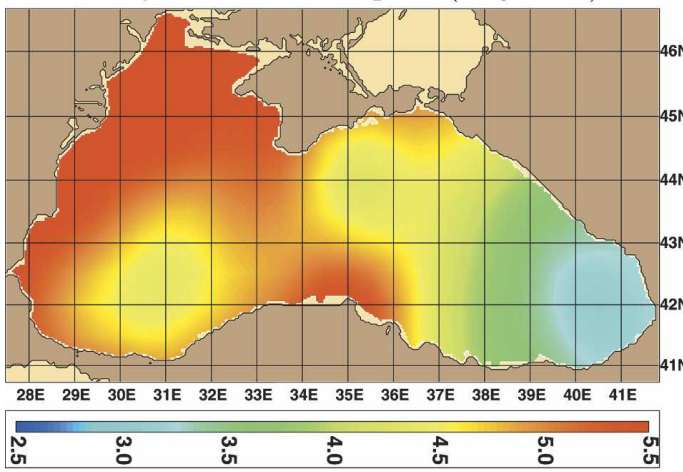

QuikSCAT wind speed (July 2003)

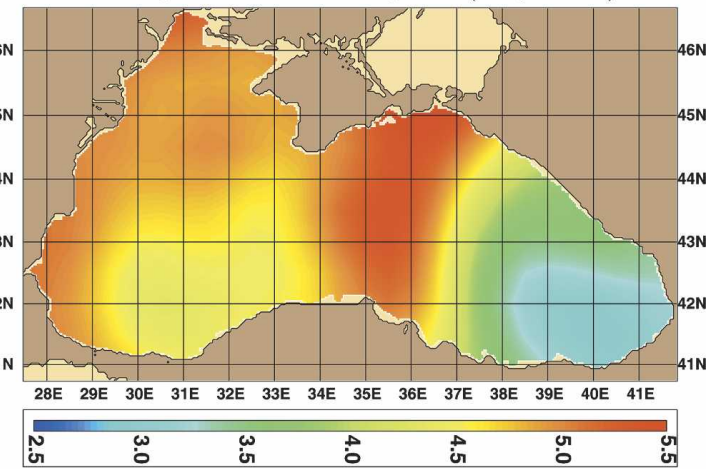

(b) Wind speed magnitude $\left(\mathrm{m} \mathrm{s}^{-1}\right)$ before and after the creeping sea-fill

ECMWF wind speed (July 2000)
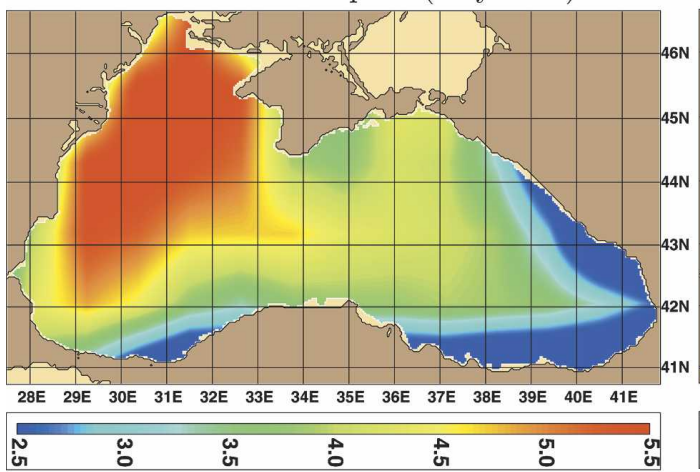

After applying the creeping sea-fill

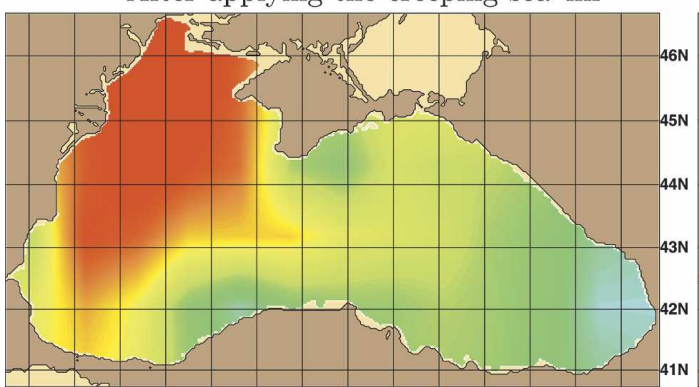

28E 29E 30E 31E 32E $33 \mathrm{E}$ 34E $35 \mathrm{E}$ 36E $37 \mathrm{E}$ 38E $39 \mathrm{E} \quad 40 \mathrm{E} \quad 41 \mathrm{E}$

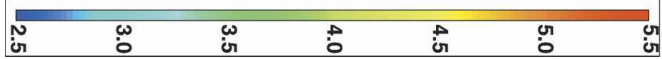

ECMWF wind speed (July 2003)

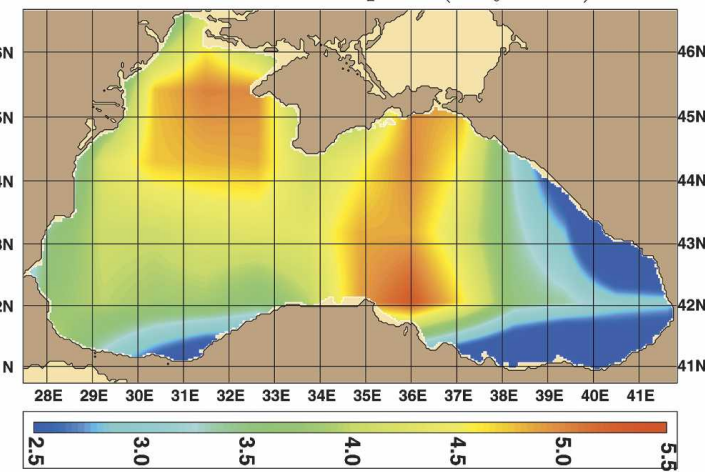

After applying the creeping sea-fill

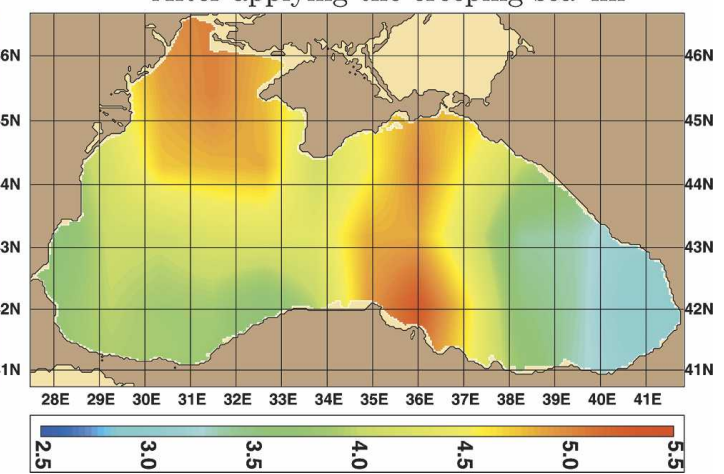

FIG. 5. Spatial variations of monthly mean wind speed at $10 \mathrm{~m}$ above the sea surface for (a) QuikSCAT and (b) operational ECMWF during July 2000 and July 2003. The mean wind speed from ECMWF is shown before and after the creeping sea-fill methodology is applied. Note that unlike ECMWF, QuikSCAT wind speeds do not have any land contamination because all satellite measurements are over the water.

After the creeping sea fill is applied to the original ECMWF wind speed fields (Fig. 5b), the coastal region wind speeds are drastically increased, and are more consistent with the QuikSCAT wind speeds. The success of the methodology is clearly evident because the sea-filled wind speeds from ECMWF agree well with those from QuikSCAT near the land-sea boundaries.
Similar results are found when wind speed from NOGAPS and QuikSCAT are analyzed (not shown).

During July 2003 the wind speeds from ECMWF did not become as strong as those from QuikSCAT in the southwestern Black Sea, even after the creeping sea fill was applied. However, this is not an artifact of the methodology because original wind speeds in this re- 
gion, just outside the land-sea mask, were already too weak, resulting in sea-filled wind speeds that are too low near the land-sea boundary.

There is serious land contamination in the wind speed near the coastal regions of the northwestern shelf (Fig. 5b), where nearly $100 \%$ of the values over water are contaminated by the land values (Fig. 2a). After the creeping sea fill is applied, the original wind speeds $\left(\sim 4 \mathrm{~m} \mathrm{~s}^{-1}\right)$ become stronger $\left(\geq 5 \mathrm{~m} \mathrm{~s}^{-1}\right)$ near the coastal boundary of this specific region during July 2003. The strong winds are consistent with those from the QuikSCAT data, demonstrating the success of the methodology. A similar increase in wind speeds, which agrees with QuikSCAT, is also seen near the same coastal regions during July 2000 after the creeping sea fill is applied. In the interior where the creeping sea fill is not applied, of course, wind speeds remain unchanged.

Similar to the analyses presented in section 3, overall statistics (i.e., ME and rms difference) are calculated for the monthly mean wind speed fields from ECMWF (Fig. 6a) and NOGAPS (Fig. 6b) with respect to those from QuikSCAT. All statistics are based on time series of 48 monthly mean values at each grid point during 2000-03, which are then mapped over the Black Sea. Results are shown before and after the creeping sea fill is applied to the wind speeds from both products, separately. A marked improvement in the accuracy of seafilled wind speed fields from ECMWF and NOGAPS is seen near the coastal regions. Mean bias is significantly reduced around the periphery of the Black Sea during $2000-03$. For example, a wind speed bias $\approx-2.5 \mathrm{~m} \mathrm{~s}^{-1}$ with respect to QuikSCAT becomes almost zero in the region south of $42^{\circ} \mathrm{N}$ after the creeping sea fill is applied. This bias reduction occurs for both ECMWF and NOGAPS.

A noteworthy improvement in wind speed accuracy is also evident on the northwestern shelf (Figs. 6a,b). Consistent with the mean bias maps, the sea-filled wind speeds from ECMWF and NOGAPS result in significant reductions in the rms wind speed difference with respect to QuikSCAT near the coastal boundaries (e.g., from $>2.5$ to $\sim 0.5 \mathrm{~m} \mathrm{~s}^{-1}$ near the coastal regions south of $\left.42^{\circ} \mathrm{N}\right)$.

Similar to the areal averaging performed for statistical metrics used to evaluate HYCOM SST performance, the process is repeated for monthly winds during 2000-03. Mean wind speed error and rms wind speed difference are calculated near the southern boundary between $41.77^{\circ}$ and $36.00^{\circ} \mathrm{E}$ where there are very low wind speeds existing in the original ECMWF and NOGAPS fields (Fig. 5b). The region where areal averages are calculated can be seen from the box marked with 2 (Fig. 1).

In Fig. 7 monthly mean wind speeds from ECMWF and NOGAPS are evaluated in comparison to those from QuikSCAT within $10 \mathrm{~km}$ of the southern model boundary during 2000-03. Errors in monthly mean wind speed are greatly reduced after applying the creeping sea fill. In particular, mean wind speed error of $3 \mathrm{~m} \mathrm{~s}^{-1}$ becomes almost zero, and the rms wind speed difference, which can be $>3 \mathrm{~m} \mathrm{~s}^{-1}$, reduces to $<1$ $\mathrm{m} \mathrm{s}^{-1}$. The areal averaging performed within different distances of the southern model boundary further confirms the success of the creeping sea fill used for monthly mean wind speed (Table 2). An interesting feature of error analysis between ECMWF and NOGAPS is that the poor agreement in wind speeds between the two archived gridded products before the creeping sea fill turns into quite good agreement after the creeping sea fill, something that ocean, atmosphere, and coupled atmospheric-oceanic modelers need to know.

Zonally averaged mean wind speed error and rms wind speed difference are further calculated for the entire Black Sea to examine overall performance of the creeping sea fill. The agreement between sea-filled wind speeds from the coarse-resolution gridded products and those from QuikSCAT is quite remarkable near land-sea boundaries (Fig. 8). In particular, the zonally averaged mean wind speed bias and rms wind speed difference for ECMWF and NOGAPS are significantly reduced at all latitude belts, especially on the northwestern shelf where there is large amount of land contamination in wind speed (section 2).

In the interior of the Black Sea, wind speeds from the archived gridded products already agree with those from QuikSCAT within reasonable accuracies (e.g., almost no mean bias and rms difference $\leq 0.7 \mathrm{~m} \mathrm{~s}^{-1}$ ) during 2000-03. Such differences in the interior are small given the fact that QuikSCAT has its own error, especially at low wind speeds, as mentioned previously.

A summary of basin-averaged wind speed error statistics between the gridded products and QuikSCAT also demonstrates the success of the creeping sea fill (Table 3). The basin-averaged rms wind speed difference between ECMWF and QuikSCAT $\left(1.6 \mathrm{~m} \mathrm{~s}^{-1}\right)$ is significantly reduced after the creeping sea fill is applied to the uncorrected fields $\left(0.7 \mathrm{~m} \mathrm{~s}^{-1}\right)$ during 2000 03. The basin-averaged mean wind speed bias between original (sea filled) ECMWF and QuikSCAT is $-1.3 \mathrm{~m} \mathrm{~s}^{-1}\left(-0.3 \mathrm{~m} \mathrm{~s}^{-1}\right)$. Similar improvements for the sea-filled wind speeds from NOGAPS are also evident 
(a) Wind speed statistics: ECMWF versus QuikSCAT.

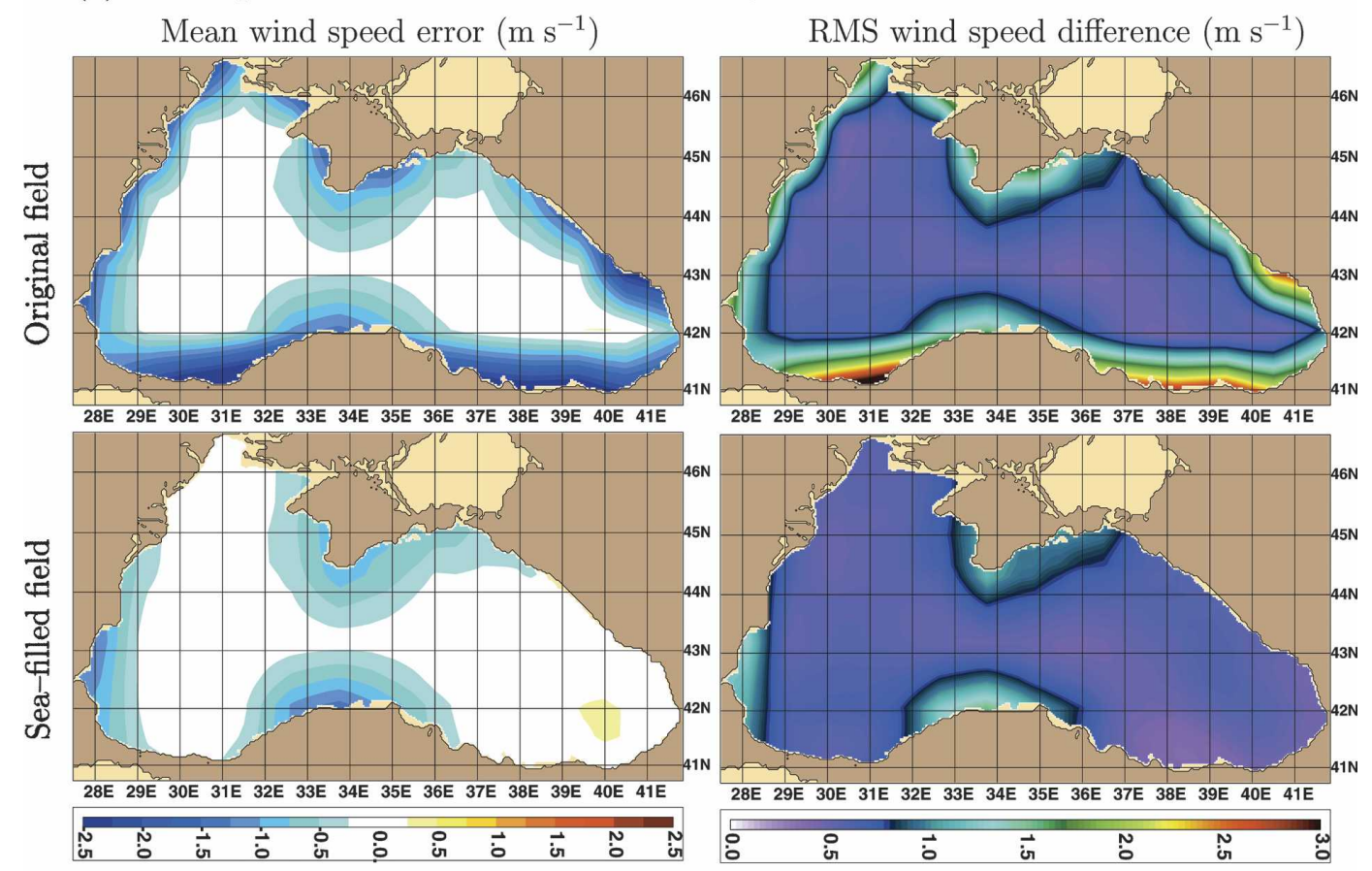

(b) Wind speed statistics: NOGAPS versus QuikSCAT.

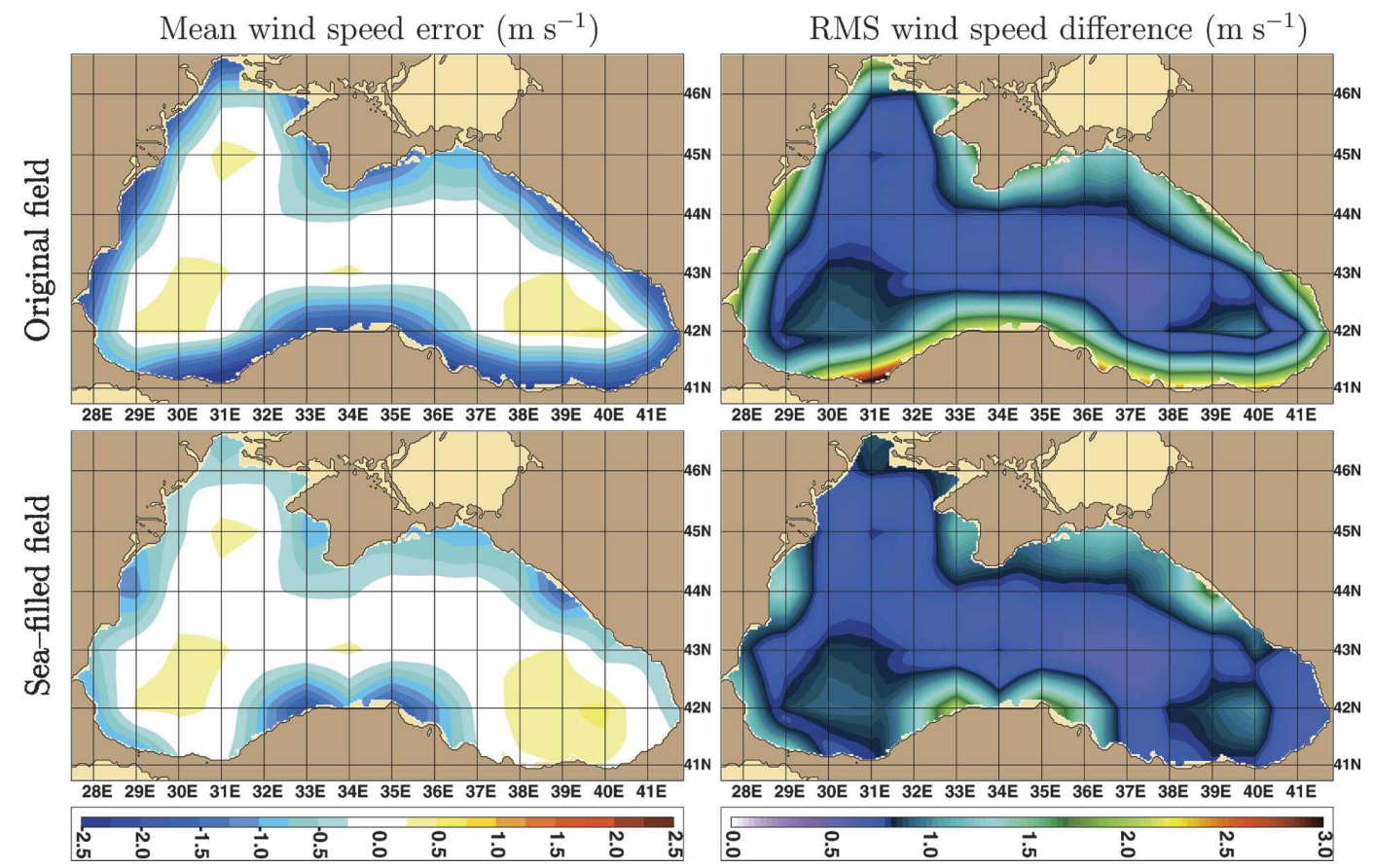

FIG. 6. Spatial mean error and rms wind speed difference maps for (a) ECMWF and (b) NOGAPS with respect to QuikSCAT. Comparisons are performed spanning 2000-03.

from Table 3. The reduction in mean bias and rms difference is due entirely to improved accuracy in the seafilled wind speed magnitudes near the coastal boundaries. The good agreement that ECMWF and NOGAPS already have with QuikSCAT in the interior of the Black Sea (Figs. 6a,b) facilitates this improvement by providing accurate boundary conditions for the creeping sea fill. 


\section{- Gridded product has uncorrected wind speed Gridded product has sea-filled wind speed}

(a) ECMWF vs QuikSCAT

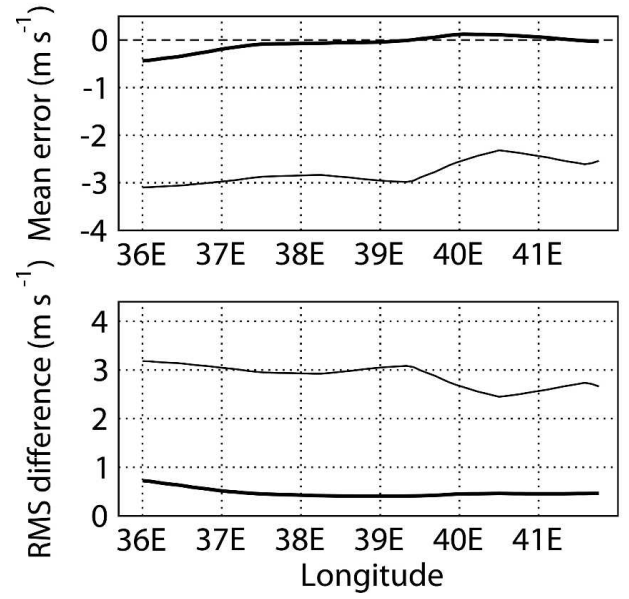

(b) NOGAPS vs QuikSCAT
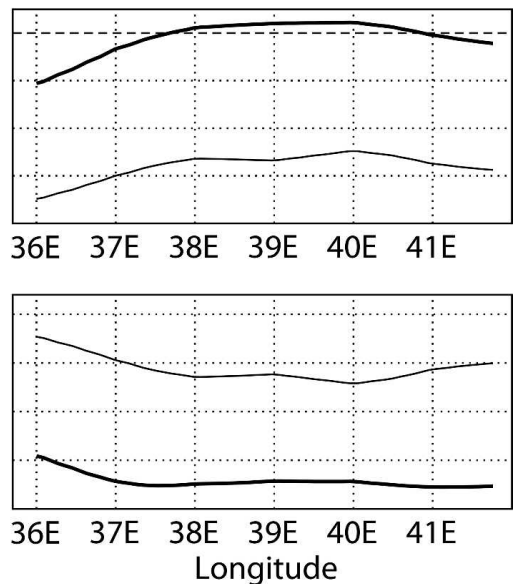

FIG. 7. Areal averages of mean wind speed error and $\mathrm{rms}$ wind speed difference with respect to the monthly QuikSCAT winds, calculated using values at all model grid points within $10 \mathrm{~km}$ of the southern model boundary from $41.77^{\circ}$ to $36.00^{\circ} \mathrm{E}$. The values are shown before (thin solid line) and after (thick solid line) applying the creeping sea fill to monthly wind speed fields from (a) ECMWF and (b) NOGAPS during 2000-03.

ECMWF and NOGAPS have different land-sea mask fields, as discussed in section 2. This probably contributes to the large differences between the two original wind speed fields near land-sea boundaries
(Table 3). Not surprisingly, sea-filled wind speeds from ECMWF and NOGAPS agree much better than those from the uncorrected fields. For example, basinaveraged mean bias between the two (NOGAPS wind

TABLE 2. Areal averages of mean error and rms difference for monthly mean wind speed at $10 \mathrm{~m}$ above the sea surface between ECMWF and QuikSCAT, NOGAPS and QuikSCAT, and ECMWF and NOGAPS during 2000-03. In the latter (i.e., ECMWF vs NOGAPS), mean error is expressed as ECMWF - NOGAPS, indicating that winds from NOGAPS are slightly stronger than those from ECMWF. Areal averages are given within various distances from the southern model boundary between $41.77^{\circ}$ and $36.00^{\circ} \mathrm{E}$, spanning latitude belts south of $43.00^{\circ} \mathrm{N}$ (see the box marked with 2 in Fig. 1). The statistics are calculated before and after the creeping sea fill is applied to monthly mean wind speeds from ECMWF and NOGAPS, separately.

\begin{tabular}{|c|c|c|c|c|c|c|c|c|c|c|}
\hline \multirow[b]{2}{*}{ Error } & \multirow[b]{2}{*}{ Creeping sea fill } & \multicolumn{9}{|c|}{ Zonal distance $(\mathrm{km})$ from the model boundary } \\
\hline & & 10 & 30 & 50 & 70 & 90 & 110 & 130 & 150 & 170 \\
\hline \multicolumn{11}{|c|}{ ECMWF vs QuikSCAT } \\
\hline \multirow[t]{2}{*}{$\mathrm{ME}\left(\mathrm{m} \mathrm{s}^{-1}\right)$} & No & -2.8 & -2.6 & -2.4 & -2.2 & -2.0 & -1.7 & -1.5 & -1.4 & -1.4 \\
\hline & Yes & -0.1 & 0.0 & 0.0 & 0.0 & 0.0 & 0.0 & 0.0 & 0.0 & 0.0 \\
\hline \multirow[t]{2}{*}{$\operatorname{Rms}\left(\mathrm{m} \mathrm{s}^{-1}\right)$} & No & 2.9 & 2.7 & 2.5 & 2.3 & 2.1 & 1.8 & 1.7 & 1.7 & 1.6 \\
\hline & Yes & 0.5 & 0.5 & 0.5 & 0.4 & 0.4 & 0.4 & 0.4 & 0.4 & 0.4 \\
\hline \multicolumn{11}{|c|}{ NOGAPS vs QuikSCAT } \\
\hline \multirow{2}{*}{$\operatorname{ME}\left(\mathrm{m} \mathrm{s}^{-1}\right)$} & No & -2.8 & -2.6 & -2.4 & -2.2 & -2.0 & -1.6 & -1.6 & -1.5 & -1.5 \\
\hline & Yes & -0.1 & -0.1 & 0.0 & 0.0 & 0.0 & 0.0 & 0.0 & 0.0 & 0.0 \\
\hline \multirow[t]{2}{*}{$\mathrm{Rms}\left(\mathrm{m} \mathrm{s}^{-1}\right)$} & No & 2.8 & 2.7 & 2.5 & 2.3 & 2.1 & 1.8 & 1.8 & 1.8 & 1.7 \\
\hline & Yes & 0.8 & 0.8 & 0.8 & 0.8 & 0.8 & 0.7 & 0.7 & 0.7 & 0.7 \\
\hline \multicolumn{11}{|c|}{ ECMWF vs NOGAPS } \\
\hline \multirow[t]{2}{*}{$\mathrm{ME}\left(\mathrm{m} \mathrm{s}^{-1}\right)$} & No & -2.8 & -2.6 & -2.4 & -2.2 & -2.0 & -1.7 & -1.6 & -1.6 & -1.5 \\
\hline & Yes & 0.0 & 0.0 & 0.0 & 0.0 & 0.0 & 0.0 & 0.0 & 0.0 & 0.0 \\
\hline \multirow[t]{2}{*}{$\mathrm{Rms}\left(\mathrm{m} \mathrm{s}^{-1}\right)$} & No & 2.9 & 2.7 & 2.5 & 2.3 & 2.1 & 1.8 & 1.8 & 1.7 & 1.7 \\
\hline & Yes & 0.5 & 0.5 & 0.5 & 0.4 & 0.4 & 0.4 & 0.4 & 0.4 & 0.4 \\
\hline
\end{tabular}




\section{$\longrightarrow$ Gridded product has uncorrected wind speed - Gridded product has sea-filled windspeed}

(a) ECMWF vs QuikSCAT

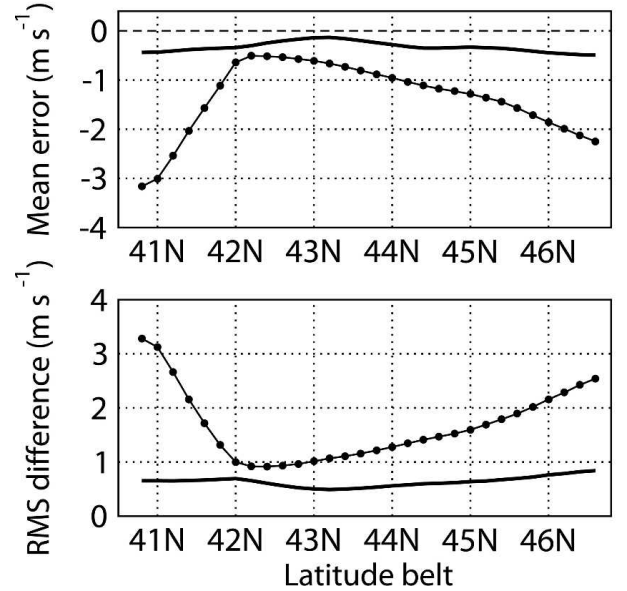

(b) NOGAPS vs QuikSCAT

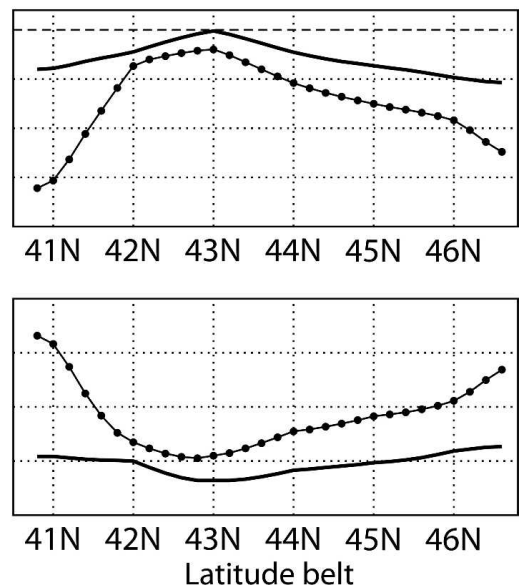

FIG. 8. Zonal averages of mean wind speed biases and rms wind speed differences calculated with respect to monthly mean wind speed measurements constructed from the SeaWinds scatterometer on the QuikSCAT satellite during 2000-03. They are shown before (thick solid line with filled circles) and after (solid line) applying the creeping sea fill to wind fields from ECMWF and NOGAPS, separately: (a) ECMWF vs QuikSCAT and (b) NOGAPS vs QuikSCAT. Zonal averaging was performed at each $\sim 0.20^{\circ}$ latitude interval.

speed subtracted from ECMWF) is $-1.2 \mathrm{~m} \mathrm{~s}^{-1}(-0.3$ $\mathrm{m} \mathrm{s}^{-1}$ ) during 2000-03 before (after) the creeping sea fill is used.

\section{Conclusions}

A methodology that uses a simple creeping sea fill is introduced to reduce land contamination in the atmospheric variables in coastal regions, providing overocean fields that are more suitable for eddy-resolving ocean model simulations and other offshore applications. The creeping sea fill is applied to scalar atmospheric forcing variables used in climatologically forced OGCM simulations. The eddy-resolving $\left[{ }^{1} / 25^{\circ} \times\right.$ $1 / 25^{\circ} \cos ($ lat); (longitude $\times$ latitude; $\sim 3.2 \mathrm{~km}$ )] OGCM is the Black Sea Hybrid Coordinate Ocean Model (HYCOM).

The model performance, with and without the use of sea-filled scalar atmospheric forcing variables, is assessed by comparison of model-calculated monthly mean SST with independent satellite-based Pathfinder values, when the model uses two distinct sources for the gridded atmospheric forcing products (ERA-15 and NOGAPS). The comparisons demonstrate problems that can occur when using atmospheric variables interpolated from a coarse-resolution grid $\left(1.125^{\circ} \times 1.125^{\circ}\right.$ for ERA- 15 and $1.0^{\circ} \times 1.0^{\circ}$ for NOGAPS) in forcing a much finer-resolution ocean model. Using only overocean values through a creeping sea-fill interpolation technique can significantly improve near-coast scalar forcing fields, resulting in significant improvements in sea surface temperature (SST) simulations from an atmospheric-forced ocean model (i.e., no assimilation of any SST data and no relaxation to any SST climatology). In particular, the areal average of mean SST bias from HYCOM with respect to the $\sim 9 \mathrm{~km}$ Pathfinder climatology is $-3.0^{\circ} \mathrm{C}\left(-0.4^{\circ} \mathrm{C}\right)$ within $10 \mathrm{~km}$ from the

TABLE 3. Basin-averaged mean error and rms differences for wind speed at $10 \mathrm{~m}$ above the sea surface between ECMWF and QuikSCAT, NOGAPS and QuikSCAT, and ECMWF and NOGAPS during 2000-03. In the latter (i.e., ECMWF vs NOGAPS), mean error is expressed as ECMWF - NOGAPS, indicating that winds from NOGAPS are slightly stronger than those from ECMWF. Note that basin-averaged statistics are calculated before and after the creeping sea fill is applied to the wind speeds from ECMWF and NOGAPS, separately.

\begin{tabular}{lccc}
\hline \hline Wind speed comparisons & $\begin{array}{c}\text { Creeping } \\
\text { sea fill }\end{array}$ & $\begin{array}{c}\mathrm{ME} \\
\left(\mathrm{m} \mathrm{s}^{-1}\right)\end{array}$ & $\begin{array}{c}\mathrm{Rms} \\
\left(\mathrm{m} \mathrm{s}^{-1}\right)\end{array}$ \\
\hline ECMWF vs QuikSCAT & No & -1.3 & 1.6 \\
& Yes & -0.3 & 0.7 \\
NOGAPS vs QuikSCAT & No & -1.3 & 1.7 \\
& Yes & -0.5 & 0.9 \\
ECMWF vs NOGAPS & No & -1.2 & 1.4 \\
& Yes & -0.3 & 0.7 \\
\hline
\end{tabular}


southeastern coast when forcing the model with the original (sea filled) atmospheric variables from ERA15. Similarly, the corresponding areal average of mean SST bias from $\mathrm{HYCOM}$ is $-3.0^{\circ} \mathrm{C}\left(-1.3^{\circ} \mathrm{C}\right)$ in the NOGAPS-forced simulation. NOGAPS has a relatively accurate land-sea mask compared to ERA-15, resulting in a smaller reduction in mean SST bias. For both simulations, there is also a significant drop (as large as $2^{\circ} \mathrm{C}$ ) in rms SST difference after using the sea-filled atmospheric variables in forcing the model simulations.

The creeping sea-fill methodology is also directly evaluated using satellite-based wind speeds obtained from the SeaWinds scatterometer on the QuikSCAT satellite on interannual time scales. Specifically, monthly mean winds from operational ECMWF and NOGAPS are compared to those from QuikSCAT to determine the validity and accuracy of the methodology on interannual monthly means from 2000 through 2003. Validations are performed before and after the creeping sea fill is applied to wind speeds from the gridded products. Because all satellite measurements are over water (i.e., no land contamination), comparisons against QuikSCAT offer a valuable evaluation for wind speeds from ECMWF and NOGAPS, especially near land-sea boundaries.

Original wind speed values from ECMWF and NOGAPS give large mean biases (even $\geq 3 \mathrm{~m} \mathrm{~s}^{-1}$ ) with respect to QuikSCAT near coastal boundaries. However, sea-filled wind speed values from both products result in significantly better agreement in comparison to those from QuikSCAT, reducing the mean bias to almost zero during 2000-03. Thus, the creeping sea-fill methodology applied to wind speeds from both products largely eliminates land contamination in the wind speed field near the land-sea boundaries. Similar improvements in the accuracy of wind speeds are also evident from rms differences, dropping from $\sim 2-3$ (before the creeping sea fill) to $\sim 0.5 \mathrm{~m} \mathrm{~s}^{-1}$ (after the creeping sea fill) near most of the land-sea boundaries.

Mean wind speed bias for ECMWF and NOGAPS with respect to QuikSCAT clearly reveals that use of the creeping sea fill significantly improves the accuracy of wind speeds near land-sea boundaries over the 48month period during 2000-03. However, problems still remain with the wind direction, which will require additional correction, as the creeping sea-fill methodology presented in this paper is not designed for vector quantities (e.g., to correct wind direction).

For many studies, where an accurate representation of the ocean dynamics and thermal field is needed close to the coastline, using a procedure such as the one proposed in this paper is one option to reduce the land contamination from atmospheric forcing fields near the land-sea boundaries. However, such a methodology may still be unable to recover specific and relevant structures inherent to a contrast (in topography, roughness, and thermal capacity) between the ocean shelf and the adjacent continent. It is also possible that wind speed from ECMWF and NOGAPS in the interior could be already too high/low in comparison to observations. This will negatively affect accuracy of wind speed near the coastal regions after the creeping sea fill is applied.

Finally, the availability of satellite-derived wind data with a higher spatial resolution than that provided from archived weather center analyses (e.g., ECMWF and NOGAPS), combined with the development of regional coupled ocean-atmosphere models, offer additional promising leads. Thus, more detailed studies dedicated to atmospheric forcing near land-sea boundaries are needed. In addition, operational weather center [e.g., ECMWF, FNMOC, and the National Centers for Environmental Prediction (NCEP)] products should provide atmospheric forcing variables on their "computational" model grid (rather than a subsampled grid) so that they can be used directly for forcing fineresolution OGCMs, a process that will certainly improve the quality of simulations especially near landsea boundaries. A computational grid archive of NOGAPS fields (ongoing from 2004) from FNMOC was completed at the Naval Research Laboratory (NRL).

Acknowledgments. We thank M. Bourassa of the Florida State University and D. Smith of the Remote Sensing Systems for numerous discussions about QuikSCAT wind measurements. Appreciation is extended to the reviewers whose helpful comments improved the quality of this paper. This paper is a contribution to the 6.1 Global Remote Littoral Forcing via Deep Water Pathways project, and the National Ocean Partnership Program (NOPP) project, U.S. GODAE: Global Ocean Prediction with the Hybrid Coordinate Ocean Model (HYCOM) funded by the Office of Naval Research (ONR).

\section{REFERENCES}

Beckers, J.-M., M. Grégoire, J. C. J. Nihoul, E. V. Stanev, J. Staneva, and C. Lancelot, 2002: Modelling the Danubeinfluenced shelf of the Black Sea. I: Hydrodynamical processes simulated by 3-D and box models. Estuarine, Coastal Shelf Sci., 54, 453-472.

Beljaars, A. C. M., and A. A. M. Holtslag, 1991: Flux parameterization over land surfaces for atmospheric models. J. Appl. Meteor., 30, 327-341. 
Bleck, R., 2002: An oceanic general circulation model framed in hybrid isopycnic-Cartesian coordinates. Ocean Modell., 4, 55-88.

Bourassa, M. A., D. G. Vincent, and W. L. Wood, 1999: A flux parameterization including the effects of capillary waves and sea state. J. Atmos. Sci., 56, 1123-1139.

— D. M. Legler, J. J. O'Brien, and S. R. Smith, 2003: SeaWinds validation with research vessels. J. Geophys. Res., 108, 3019, doi:10.1029/2001JC001028.

Burrough, P. A., and R. A. McDonnell, 1998: Principles of Geographical Information Systems. Oxford University Press, 333 pp.

Casey, K. S., and P. Cornillon, 1999: A comparison of satellite and in situ-based sea surface temperature climatologies. J. Climate, 12, 1848-1863.

Chelton, D. B., J. C. Ries, B. J. Haines, L. L. Fu, and P. Callahan, 2001: Satellite altimetry. Satellite Altimetry and Earth Sciences, L. L. Fu and A. Cazanave, Eds., Academic Press, 5764.

Donelan, M. A., W. M. Drennan, and K. B. Katsaros, 1997: The air-sea momentum flux in conditions of wind sea and swell. $J$. Phys. Oceanogr., 27, 2087-2099.

Gibson, J. K., P. Kållberg, S. Uppala, A. Hernandez, A. Nomura, and E. Serrano, 1999: ERA description (Version 2). ECMWF Re-Analysis Project Report Series 1, 74 pp.

Halliwell, G. R., Jr., 2004: Evaluation of vertical coordinate and vertical mixing algorithms in the Hybrid Coordinate Ocean Model (HYCOM). Ocean Modell., 7, 285-322.

Kara, A. B., A. J. Wallcraft, and H. E. Hurlburt, 2005a: A new solar radiation penetration scheme for use in ocean mixed layer studies: An application to the Black Sea using a fine resolution Hybrid Coordinate Ocean Model (HYCOM). J. Phys. Oceanogr., 35, 13-32. $\longrightarrow,-$ and $-2005 \mathrm{~b}$ : Sea surface temperature sensitivity to water turbidity from simulations of the turbid Black Sea using HYCOM. J. Phys. Oceanogr., 35, 33-54.

- H. E. Hurlburt, A. J. Wallcraft, and M. A. Bourassa, 2005c: Black Sea mixed layer sensitivity to various wind and thermal forcing products on climatological time scales. J. Climate, $\mathbf{1 8}$ 5266-5293.

Large, W. G., G. Danabasoglu, S. C. Doney, and J. C. McWilliams, 1997: Sensitivity to surface forcing and boundary layer mixing in a global ocean model: Annual mean climatology. $J$. Phys. Oceanogr., 27, 2418-2447.

Liu, W. T., and W. Tang, 1996: Equivalent neutral wind. JPL Rep. 96-17, 8 pp

Mahrt, L., 2000: Surface heterogeneity and vertical structure of the boundary layer. Bound.-Layer Meteor., 96, 33-62.

Offerle, B., C. S. B. Grimmond, and T. R. Oke, 2003: Parameterization of net all-wave radiation for urban areas. J. Appl. Meteor., 42, 1157-1173.

Pegion, P. J., M. A. Bourassa, D. M. Legler, and J. J. O'Brien, 2000: Objectively derived daily "winds" from satellite scatterometer data. Mon. Wea. Rev., 128, 3150-3168.

Rosmond, T. E., J. Teixeira, M. Peng, T. F. Hogan, and R. Pauley, 2002: Navy Operational Global Atmospheric Prediction System (NOGAPS): Forcing for ocean models. Oceanography, 15, 99-108.

Samelson, R. M., 1992: Supercritical marine boundary layer flow along a smoothly varying coastline. J. Atmos. Sci., 49, 15711584.

Schrum, C., J. Staneva, E. Stanev, and E. Ozsoy, 2001: Air-sea exchange in the Black Sea estimated from atmospheric analysis for the period 1979-1993. J. Mar. Syst., 31, 3-19.

Stull, R. B., 1988: An Introduction to Boundary Layer Meteorology. Kluwer, 666 pp. 